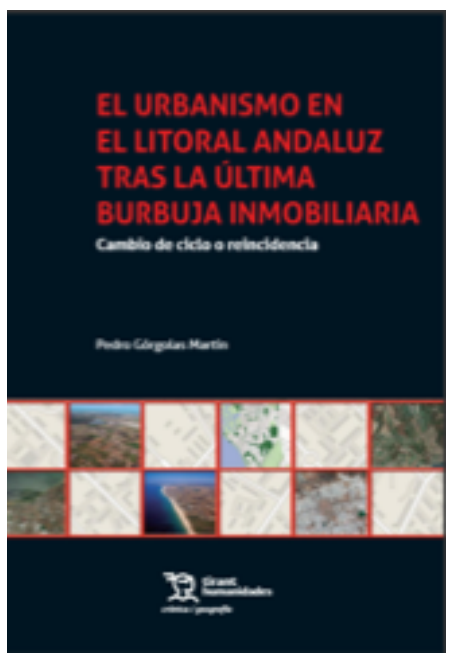

Entre los procesos territoriales más relevantes desarrollados en las últimas décadas en el ámbito mediterráneo, le corresponde sin duda un lugar de primer orden a la urbanización del litoral. Son numerosas las voces que se han levantado alertando sobre la velocidad y la magnitud de la ocupación de los suelos costeros, vinculada en gran medida al papel económico que la actividad turística desempeña en buena parte de los países del sur de Europa. En el caso español, esos procesos urbanizadores del espacio litoral, asociados al boom inmobiliario experimentado durante el periodo 1997-2007, han revestido una especial gravedad, sobre la que se ha venido llamando la atención en numerosos estudios recientes, estimándose que en torno al $35 \%$ de la superficie

\section{¿HACIA UN CAMBIO DE CICLO EN EL URBANISMO DEL LITORAL?}

Victoriano Sainz-Gutiérrez. Universidad de Sevilla, Sevilla, España.

Título libro: El urbanismo en el litoral andaluz tras la última burbuja inmobiliaria Autor: Pedro Górgolas Martín Edición: Valencia: Tirant Humanidades, 2020 (215 págs.) ISBN: 978-84-I7973-IO-O

del frente marítimo, en la franja más próxima a la línea de costa, está ya construida en la costa mediterránea española (Estévez, Prieto \& Alfonso, 2016).

Como no podía ser menos, esta realidad ha generado una intensa controversia desde el punto de vista tanto sociopolítico como disciplinar, habiéndose puesto en marcha diferentes intentos de regulación de los usos del suelo en un espacio tan sensible en lo ambiental, en lo económico y en lo paisajístico. No han faltado, claro está, los planes de ordenación que se han ocupado de establecer directrices para hacer efectivo el control del crecimiento urbanístico en el litoral mediterráneo español (Rullán, 2011); cuestión diferente es la eficacia que esos instrumentos hayan podido tener a la hora 
de poner límites a los múltiples abusos perpetrados en los años de la última burbuja inmobiliaria. A esta cuestión está dedicado un reciente trabajo de Pedro Górgolas, en el que analiza en qué medida el planeamiento urbanístico y territorial puede haber contribuido a contener el proceso urbanizador en la costa andaluza o a acelerarlo.

El autor ya había dedicado unas interesantes páginas al nonato Plan de Protección del Corredor del Litoral de Andalucía (Górgolas, 2019, pp. 71-93), pero en este nuevo libro se centra en el estudio de los modelos territoriales con los que ha venido funcionando el litoral andaluz, a partir del examen del planeamiento municipal y de la planificación territorial en vigor en cada una de las unidades territoriales delimitadas con base en el Plan de Ordenación del Territorio de Andalucía. El principal problema detectado tiene que ver con la existencia, en la mayoría de los municipios litorales, de un planeamiento urbanístico claramente expansivo, pensado para poner a disposición del mercado inmobiliario cantidades desproporcionadas de suelo urbanizable, que han terminado generalizando un modelo de urbanización residencial, dispersa y de baja densidad, en las zonas interiores del traspaís.

Al estudio de esta preocupante expansividad territorial se dedica el primer capítulo del libro. Sobre la base del establecimiento de algunos indicadores que permiten hacerse cargo del alcance de los procesos en curso, se realiza un doble análisis de los datos que ofrecen los planes generales municipales: de una parte, se mide la relación entre la superficie del suelo urbano clasificado por esos planes y la población censada del municipio, con objeto de hacerse una idea del grado de dispersión urbana existente; de otra, se determina la proporción de suelo urbanizable clasificado en función del urbano, con el fin de conocer las expectativas de crecimiento en cada término municipal. La conclusión es que son los centros regionales los que presentan un crecimiento más mesurado; en cambio, los tramos de costa donde la urbanización turística es predominante tienen unos porcentajes de crecimiento claramente excesivos.

En este contexto, se dedica una particular atención a la parte occidental de la llamada Costa del Sol para intentar precisar sus rasgos diferenciales, habida cuenta de que se trata del principal destino turístico de la región andaluza. Entre los diferentes aspectos subrayados por Górgolas, el más llamativo tal vez sea cómo en este ámbito la estrategia de ordenación contenida en los planes urbanísticos revela una tendencia claramente orientada al monocultivo residencial, resultando llamativamente baja la edificabilidad destinada al desarrollo de alojamientos específicamente turísticos. Si hubiéramos de buscar la causa de este inquietante fenómeno, probablemente tendríamos que acudir a la frecuente connivencia entre el poder local y los promotores inmobiliarios, en el marco de ese urbanismo realizado a golpe de convenios que ha caracterizado el planeamiento urbano en la Espańa de los años noventa.

El otro gran problema territorial sobre el que se pone foco es el de la creciente presencia de asentamientos irregulares en el suelo rústico, muchos de los cuales constituyen verdaderos desarrollos urbanísticos, infradotados y con bajísimos niveles de urbanización. Aquí el territorio más afectado no es tanto el de la provincia de Málaga como 
el de la de Cádiz, siendo Chiclana uno de los municipios más significativos a este respecto. Esta preocupante realidad ha sido objeto de un reciente estudio para el ámbito andaluz (Piñero, Sainz \& Antúnez, 2015), en el que Górgolas también ha participado como investigador; se trata, pues, de un asunto que conoce bien y sobre el cual aquí se detiene a considerar el insuficiente modo en que los planes urbanísticos lo han tratado: "El planeamiento general vigente en el litoral andaluz adolece de cierta 'pereza instrumental' en relación con esta problemática”, que hasta la fecha ha constituido sin duda un "campo minado" (p. 84) para el trabajo profesional de los urbanistas.

En el segundo capítulo se disecciona el uso dado a los planes subregionales de ordenación del territorio, que deberían haber sido -al menos, en teoría- los instrumentos a través de los cuales se hubieran podido corregir algunas de las patologías territoriales detectadas en el litoral andaluz, en especial porque la ordenación del sistema de ciudades es una de las principales cuestiones que dichos planes deben abordar. Lo sorprendente del análisis realizado a este respecto es la constatación de que los planes territoriales vigentes, en lugar de corregir aquellos criterios menos sostenibles del planeamiento urbanístico, los han validado: "En algunos casos, la planificación subregional no solo ha consentido la insostenibilidad implícita en el urbanismo expansivo de los municipios litorales, sino que ha alentado el desarrollo del crecimiento propuesto" (p. 101). La falta de adaptación de los planes generales a los criterios del Plan de Ordenación del Territorio de Andalucía ha hecho que la entrada en vigor de determinadas disposiciones de los planes subregionales haya tenido un verdadero "efecto búmeran".

Entre otras posibles manifestaciones de ese efecto, se menciona la introducción de áreas de oportunidad de carácter supramunicipal, las cuales no son tenidas en cuenta a la hora de cuantificar el crecimiento urbanístico conforme a lo establecido en la norma 45 del Plan de Ordenación del Territorio de Andalucía. El motivo de dicha exención remitía a la necesidad de dar un decidido impulso al dinamismo socioeconómico de las distintas unidades territoriales ordenadas por los planes subregionales, pero no ha sido así y la mencionada herramienta solo ha servido para confirmar la tendencia alcista del crecimiento urbanístico ya contenida en las previsiones de los planes generales municipales. Así lo demuestra el cuidadoso análisis realizado de las áreas de oportunidad en cada uno de los planes subregionales: su impacto para el conjunto del dominio territorial litoral se habría traducido en la transformación urbanística de unas 15.000 hectáreas de suelo rústico.

La conclusión a la que se llega, después de haber examinado el urbanismo desarrollado en el litoral andaluz en las últimas décadas, es que, desde la Administración regional, se ha promovido una política territorial que no duda en calificar de bipolar, por cuanto se ha movido entre dos extremos: "Por un lado, se legisla a favor de un modelo de ciudad compacta, impulsando estrategias de contención del consumo de suelo por los usos urbanos, mientras, por otro, se arbitran fórmulas que legitiman al planeamiento general para proceder a su desnaturalización, favoreciendo el establecimiento de modelos territoriales expansivos" (p. 108). Desde esta perspectiva, dicho sea de paso, se puede 
entender mejor el desdichado camino recorrido por el mencionado Plan de Protección del Corredor del Litoral de Andalucía, aprobado por un Gobierno en funciones que no podía ignorar que lo era y que estaba facilitando con ello su posterior anulación por los tribunales de justicia.

Pero Górgolas no se queda aquí, y eso es lo que, a mi entender, da más valor a su libro. Tras haber dedicado los dos primeros capítulos a esclarecer la difícil y anómala situación por la que atraviesan los territorios costeros del sur de España, entra en el tercer capítulo a plantear diversas propuestas que podrían ayudar a revertirla. Para ello distingue tres situaciones básicas, a las que resulta necesario responder con diferentes estrategias: la primera de ellas es la denominada "periferia fraudulenta", fruto de la suburbanización irregular existente; la segunda es la "periferia nonata", constituida por aquellos suelos urbanizados y no edificados por temor de la última crisis económica; y la tercera es la "periferia expectante", asociada a los suelos urbanizables clasificados por el planeamiento vigente y aún pendientes de desarrollar.

Para la "periferia fraudulenta" se llevan a cabo diversas recomendaciones orientadas a su integración urbanoterritorial, que no pasan tanto por su normalización urbanística como por su razonable compactación, mediante la creación de centralidades periféricas que le proporcionen una mínima dosis de densidad espacio-visual, en la línea de lo que propusiera Sieverts para los "paisajes intermedios” (Górgolas, 2018). Para la "periferia nonata" y la "expectante" se propone una estrategia de reordenación que consiste en detraer aprovechamiento de esos suelos para transferirlo a otros, en la línea de la desclasificación y el decrecimiento del que hablara Latouche al presentar la idea de límite como sinónimo de contención frente al desarrollismo. Estas son algunas de las claves que se aportan para lograr un verdadero cambio de ciclo en el urbanismo andaluz, toda vez que la tendencia que se observa en estos momentos de crisis es la de limitarse a esperar tiempos mejores para seguir haciendo más de lo mismo.

Los numerosos datos recogidos por el autor, los incisivos análisis que realiza y las valientes propuestas que plantea hacen que este libro, aunque trate de un ámbito espacial concreto -o quizá precisamente por ello-, sea digno de ser leído con atención por cuantos se interesan por los problemas asociados a la nueva territorialidad emergente.

\section{Referencias bibliográficas}

Estévez, R., Prieto, F. \& Alfonso, C. (2016). Cambios en la ocupación del suelo en la costa en España (1987-2011). Madrid: Observatorio de la Sostenibilidad.

Górgolas, P. (2018). Planeamiento urbano y suburbanización irregular en el litoral andaluz: directrices y recomendaciones para impulsar la integración urbanoterritorial de asentamientos. Ciudad y Territorio. Estudios Territoriales, 40(195), 33-52. https://dialnet.unirioja.es/ejem plar/483233

Górgolas, P. (2019). Dos décadas de urbanismo en Andalucía (1997-2017). Historia de una contradicción. Sevilla: Universidad de Sevilla \& Junta de Andalucía, col. Kora.

Latouche, S. (2014). Limite. Buenos Aires: Adriana Hidalgo. 
Piñero, A., Sainz, V. \& Antúnez, D. (2015).

El urbanismo de la no ciudad. Procesos de ocupación irregular en el suelo no urbanizable de Andalucía. Sevilla: Junta de Andalucía.

Rullán, O. (2011). La regulación del crecimiento urbanístico en el litoral mediterráneo español. Ciudad y Territorio. Estudios Territoriales, 43(168), 279-297. https://recyt.fecyt.es/index. $\mathrm{php/CyTET/article/view/76054/46454}$

Sieverts, T. (2015). Paisajes intermedios. Una interpretación de la Zwischenstadt. Málaga: Ediciones del Genal, col. 16/ dieciséis. 